\title{
Study on the Problems and Suggestions to the Sport Theory Teaching in Colleges and Universities
}

\author{
Jie Yang \\ Department of International Communication and Academic Research of CNFA \& CNBA \\ Shandong Sport University \\ Rizhao, China 276826
}

\begin{abstract}
Combining the problems in the current theoretical courses for sport with the personal teaching experience, the author conducts a study on the teaching of sport theories in some regular universities and some sport colleges by the means of literature investigation, interview and questionnaire. It is concluded that the deficiency of credit hours, the obsolete teaching materials, the poor teaching skills, the neglect of sport theories, as well as the inferior attitudes of students, are the common problems that exist in the current theoretical courses of sport. The study endeavors to find solutions to these problems, with the hope of providing reference for the current reform of theoretical courses for the majors in physical education. The value of this paper is not only trying to dig the reason and solution of "be separated" in macro level and it is, but also to do some attempts in micro level which is combining theory with practice. Suggestions: increase theoretical class teaching time appropriately; highlight the comprehensiveness and lifelong purpose of teaching materials when selecting teaching contents, select teaching materials based on actual needs; update teaching methods and means; increase the proportion of theoretical class score in total physical education score.
\end{abstract}

Keywords-physical education; theoretical course; sport theory teaching; pedagogy; colleges and universities

\section{INTRODUCTION}

In addition to getting students physically trained, physical education in colleges and universities attaches more importance to letting students master the basic theories, knowledge and methods of physical exercise. Therefore, sport theory courses must be paid attention to. However, in the present practice of physical education in Chinese colleges and universities, the common problems, including short credit hours, too much emphasis on technique, and neglect of theoretical learning, still exist. As a result, the current P.E. courses stress on training instead of education. A survey conducted in the colleges and universities of Jiangsu province, by Si Huaqin el al, shows that among the 32 colleges and universities, 26 did not meet the basic requirement for the credit hours of theoretical teaching for sport, accounting for $81.3 \%$ of the surveyed intuitions. It reaches the conclusion that the total number of theoretical course for sport is not enough, the teaching patterns of the course are not unified, the way of teaching is rather random, and the contents of teaching are out of date. All these problems reflects that the theoretical courses are out of step with the physical training and some teachers do not even want to get involved in the teaching of sport theories. The study of Gao Jun el al on the theoretical courses of sport, conducted in 68 colleges and universities (13 key universities, 55 regular colleges and universities) in 21 provinces of China, reaches to the quite similar conclusion: the scheduled credit hours are inadequate; the teaching patterns vary from teacher to teacher, from university to university; the courses divorce from physical building; and some teachers are reluctant to teach sport theories. Fifty-nine colleges and universities did not reach the required amount of credit hours, accounting for $86.8 \%$ of the surveyed. These researches show that the current situation is far away from the requirements of for theoretical course stipulated in the "Outline for the Teaching of Physical Education Curriculum in Regular Higher Education Institutions", which is made by the Ministry of Education of China.

\section{RESEARCH OBJECTS AND METHODOLOGY}

\section{A. Research Objects}

The research objects are 800 students and 33 teachers of five provincial regular colleges and universities and two sport colleges.

\section{B. Methodology}

1) Literature investigation: Through investigating a large amount of literature of sport theory teaching in China and aboard, the author analyses and utilizes the results of the previous researches and combines them with this study, trying to reach a conclusion.

2) Interview: By interviewing the P.E. teachers and students, a lot of first-hand information has been collected, including the class situation, effectiveness of teaching, attitudes of teachers and students, especially the different attitudes of teachers and students compared with before. The study is conducted through analysis and comparison.

3) Questionnaire:The questionnaire contains the questions such as the amount of credit hours, the teaching contents, the teaching pattern, the form of examination, the evaluation of the teacher. The validity of the contents of the questionnaire has been tested. One hundred copies of the 
questionnaires were distributed, and 100 were retrieved, with no invalid. The questionnaire can basically reflect the existing problems.

\section{RESEARCH RESULTS AND ANALYSIS}

\section{A. Deficiency of Credit Hours}

The scheduled credit hours of theoretical courses are inadequate, and it is quite difficult to increase the credit hour. On the one hand, according to the requirements of the Ministry of Education, the total credit hours of all curriculums in each college and university are quite fixed. To increase the amount of theoretical courses of sports is bound to reduce the credit hours of other curriculums. Adjusting the credit hour is of great difficulty for every major. On the other hand, the increase of sport theory teaching can lead to the decrease of the credit hours of physical exercise, the proportion of which is already not too large in the curriculums of regular colleges and universities. Therefore, it is neither practical nor reasonable to increase the credit hours or to enlarge the proportion of theoretical courses blindly, nor effective for the raise of students' awareness of sport theory learning.

\section{B. Obsolete Teaching Materials}

The theoretical courses of ordinary colleges are generally taught by specific sport teachers. Most of them teach on the basis of their lecture notes, without textbooks. For specific sport college students, all colleges of the nation normally adopt unified textbooks. However, the contents of some textbooks are out of date. Some books were compiled in 1990s, around 30 years ago. Even though, some principles of sport theory are unchangeable, the contents of the teaching materials should be better to be revised to adapt to the current situations, to the need of modern teaching, and to the understanding of contemporary students.

\section{Poor Teaching Skills}

For a very long period, the P.E. teachers of regular colleges and universities think that their job is to conduct good outdoor classes. Large amounts of time and energy are used in the study on techniques and technique training methods. They seldom received specific theoretical instruction before and are lack of experience in sport theory teaching, let alone doing research on pedagogy of theoretical course in sport. Even though some colleges and universities attempt to combine the great lectures of professors with the small classes of specific teachers, and adopt electronic teaching methods, the teaching patterns and teaching methods are still relatively boring, monotonous and arbitrary. Most of the students are not sport majors. It is quite easy for them to understand the theoretical courses, but their technical performance is generally mediocre. As a result, the teacher is intended to pay much more attention to the training of techniques and neglect sport theory teaching.

As for specific sport colleges, teachers and professors recognize the value of sport theory teaching, and can skillfully utilize modern teaching methods such as teaching by the means of multimedia. However, most of the students are sport majors and seldom show interest in theoretical courses, which requires the teacher to adopt diversified means of teaching master skillful teaching methods. It is quite demanding for teachers, but teachers' levels of teaching skill are uneven, leading to the unsatisfying teaching results of the course.

\section{Inferior Attitudes of Students}

The main factors that influence students on their learning in theoretical courses include the poor self-control ability, the large daily training loads, the lack of independent study ability, the deficiency of basic knowledge, as well as the inadequacy of interest in the course. Besides, with the popularization of smart phones, students' attention is more likely to be distracted. In class, a considerable number of students will use their smart phone and do something irrelevant to their study. Due to the large numbers of students of the class, the teacher cannot stop to warn the one who uses cellphone every time. Cellphone using in class is quite an urgent problem that needs to be solved.

\section{E. Some of the Students Developed an Aversion to Learning}

From there search results by Feng Chuan-cheng and the interview results of the author. The internal cause of students' weariness of learning behavior is the low level of development of internal motivation mechanism of learning. For physical education students, their foundation of culture is poor and never experiences the joy of learning success. At the same time, physical education students do not have enough understanding of learning goals, and only about $10 \%$ of them are willing to make achievements in their studies. From the psychological point of view, some of the students majoring in physical education in colleges and universities have poor mental state, weak will, poor psychological quality and poor ability in emotional control, frustration and so on. They often relax their own requirements in Learning and lack of enterprising spirit.

\section{F. Lack of Diversity in Assessment Methods}

The evaluation of learning achievement is the most basic field in the field of educational evaluation, and it is also a work that educators are most concerned about. The evaluation of students' individual learning progress and behavior change is a part of the whole teaching. At present, the evaluation of physical education theory curriculum is mostly single, which cannot reflect the combination of theory and practice, nor can it truly evaluate the whole result of students' study. Observation, interview and other inspection techniques should also be paid more attention to in the evaluation of students' learning effect, but most colleges and universities do not embody them. The results of a single observation or examination are not of great significance, which is at most the student's general performance. Evaluation is a means to determine the effectiveness of students' learning. It can enable students to affirm their own strengths, to make them realize their own shortcomings quickly, and to improve them in the later learning process. Therefore, teachers use more evaluation methods, the more targeted, the more accurate evaluation. 


\section{CONCLUSIONS AND RECOMMENDATIONS}

Physical education is an indispensable part of higher education and an important way to develop talents in an allround way. The relationship between physical Education Theory and practice is the relationship between Teaching Fishing and Giving Fish. Only by systematically mastering the methods of scientific fitness can students exercise correctly. Higher education is the activity of teaching and learning of advanced knowledge. Students should not only accept and store knowledge, but also know why. Therefore, the teaching of physical education in high education should strengthen the teaching of theoretical knowledge of sports, avoid the blindness of exercise, make the theory guide the practice of sports better, and enhance the ability of the students to contact the practice in theory.

\section{A. Research Conclusion}

The present teaching situation of physical education theory course in most colleges and universities is different from the Teaching Instruction Outline of National Physical Education Course in Ordinary Colleges and Universities, and the requirement of modern fitness sports. It mainly shows that the teaching hours of the theory course are less, the teaching material and teaching content are old, the teaching is lacking of art, the traditional theory teaching is rather monotonous, the theory is out of touch with the practice teaching, and the students' attitude towards the theory course is not active and confident. The students' self-control is poor and they have the learning weariness. In addition, a series of reasons, such as single examination mode and lack of comprehensive assessment criteria for students, make the overall effect difficult to achieve the expected results.

\section{B. Countermeasures and Suggestions}

Under the current environment, the contents, forms and methods of PE teaching should be reformed effectively and the management system of PE colleges should be improved; Improve the professional quality and sense of responsibility of teachers in physical education colleges and strengthen the teacher training system; Strengthen the course reform; Improve the adaptability of the course; Strengthen the compulsory basic course remedial study to the physical education college students; Pay attention to students' Psychological problems and cultivate healthy mentality.

The method of combining practice and theory is adopted in the teaching of physical education theory at the right time, and the students' learning motivation can be stimulated by the use of $\mathrm{TV}$, video recording, slide and computer to make full use of multimedia teaching methods. Cultivate students' adaptability; Improve the ability of mind to bear and oneself in an all-round way; Stimulate students' interest in learning; using the limited theory course, through the improvement of teachers' teaching art and the increase of students' learning enthusiasm, the learning effect can be enhanced.

Correct use of New Media platform is an effective way to widen the access to knowledge. The new media platform, such as WeChat public platform, public mailbox, WeChat public group and QQ public group, Sina Weibo, Youku video home page and other new media platforms are regarded as the database of classroom teaching of theory course, which is the concept that university teachers should have under the new situation. Through the new media platform to assist the classroom teaching of the theory course, students can get useful sports knowledge in the process of interaction with the smart machine, and find the fun of learning in the new knowledge acquisition path. Guide students to use new and high technology correctly, especially using computers and smart phones correctly.

The teaching of physical education theory in colleges and universities is still a weak link in physical education teaching. We should pay attention to the teaching of physical education theory, improve teaching methods, improve teaching environment, train students' outlook on life and values; Improve the employment environment; Arouse students' interest in physical Education. The teachers should pay attention to the diversity and flexibility of evaluation methods. Teachers should learn to use a variety of evaluation methods to correctly handle the evaluation results, make the evaluation more fair and reasonable. The students' academic achievements can be more comprehensively reflected. Achieve the ultimate goal of physical education teaching in colleges and universities.

\section{REFERENCES}

[1] Li Zeng Ji, Wu Mingzhi, LI Zhi-wei. Survey and analysis of theoretical physical education class teaching in common institutes of higher learning in China [J]. Journal of Physical Education. Jan.2007 (14-1) 95-98.

[2] Gao Jun, Qi Hanle. Investigation and Analysis of Teaching in Physical Education Theoretic Courses of Colleges and Universities in China [J]. Journal of Beijing University of Physical Education , Jan.2003 (11) 92-93.

[3] Si Huaqin, Shen Hui, ZHANG Hong- wei. Investigation and Analysis of Teaching in Physical Education Theoretic Courses of Colleges and Universities in Jiangsu [J]. Journal of Nanjing Institute of Physical Education Vol.19.No.1Feb.2005 (1) 80-82.

[4] Wang Yi. Problems and strategies of sports theory teaching in universities [J]. Journal of Sports Adult Education, Aug. 2005 (21-4) 62-63.

[5] Feng Chuancheng. Research on the Study-weariness Behavior and Influence of the Students in Sport Universities [J] Journal of Beijing Sport University Mar.2011 (34-3) 105-107.

[6] Du Lei. Investigation and analysis of theory course learning status of sports institute students in Qiqihar University [J]. Journal of Science of Teachers College and University Dec. 2016 (36-12) 62-64.

[7] Sun Tiemin. P.E. in institutes and universities in Shandong Province [J] Journal of Wuhan Institute of Physical Education. Aug.2005 (39-8) 85-87.

[8] Jing Wen, CHI Jing-lian. Reflection and Reconstruction on Sports Major's Theory Courses Classroom Teaching [J]. Journal of Beijing Sport University Jul. 2016(38-7) 98-103. 